\title{
PLANO DE PARTO: NOVAS PRÁTICAS SUGERIDAS NAS MÍDIAS SOCIAIS
}

Victória Prates Pasqualotto; Mariene Jaeger Riffel

Sugerido desde 1996 como ferramenta útil e que deve ser encorajada, o Plano de Parto foi definido como um plano pessoal elaborado pela mulher durante a gestação, conhecido pelo marido/parceiro e, se possível, pela família, que determina onde e por quem o parto deverá ser atendido. Também é prática incluída nos "10 Passos para o Pré-Natal de Qualidade" proposto pelo Ministério da Saúde, que preconiza sua elaboração a partir de informações fornecidas pelo prénatalista sobre os benefícios do parto fisiológico. Por acreditar na potencialidade do Plano de Parto e perceber nos blogs e sites ferramentas de transmissão, circulação e produção de conhecimentos que possibilitam voz às mulheres, foram elaboradas as seguintes questões norteadoras: os sites e blogs sugerem novas práticas para inclusão em Planos de Parto?; quais são estas novas práticas sugeridas? Trata-se de estudo qualitativo, exploratório, descritivo e de análise temática, que teve como objetivo descrever e analisar as sugestões de Plano de Parto disponíveis em blogs e sites. A busca pelo objeto de pesquisa foi realizada no site Google, em 200 links. $O$ total da amostra foi de 41 blogs e sites, analisados a partir da inclusão das informações em planilha de Excel e comparando-as com as práticas categorizadas pela OMS para assistência ao parto. Da análise emergiram 48 novas práticas que foram categorizadas de acordo com o momento de sua execução, ou seja: antes/durante a internação hospitalar, durante o trabalho de parto, durante o parto, no pós-parto e em caso de cesárea. Constatou-se a existência de uma rede de informações que instiga as mulheres quanto ao planejamento dos principais eventos considerados importantes para seus partos. Constatou-se, também, que os desejos das mulheres têm sido evidenciados pela internet, circulando em blogs e sites. As 48 práticas evidenciadas nem sempre são oriundas de resultados de pesquisas: muitas vezes dão voz à cidadã comum que ao expressar seus desejos e expectativas, passam a criar critérios únicos para a assistência em seus partos. Palavra-chave: Plano de Parto; Humanização do parto; Enfermagem baseada em evidências. 